\title{
Screening of RTILs for propane/propylene separation using COSMO-RS methodology
}

\author{
Marcos Fallanza a , María González-Miquel ${ }^{\mathrm{b}}$, Elia Ruiz ${ }^{\mathrm{c}}$, Alfredo Ortiz ${ }^{\mathrm{a}}$, Daniel Gorri ${ }^{\mathrm{a}}$, Jose Palomar ${ }^{\mathrm{c}}$, \\ Inmaculada Ortiz ${ }^{\mathrm{a}, *}$ \\ a Advanced Separation Processes Research Group, Departamento de Ingeniería Química y Química Inorgánica, Universidad de Cantabria, 39005 Santander, Spain \\ ${ }^{\mathrm{b}}$ Departamento de Ingeniería Química, Universidad Complutense de Madrid, 28040 Madrid, Spain \\ ` Sección de Ingeniería Química, Departamento de Química Física Aplicada, Universidad Autónoma de Madrid, Cantoblanco, 28049 Madrid, Spain
}

\section{H I G H L I G H T S}

- Prediction of solubilities and selectivities of $\mathrm{C}_{3} \mathrm{H}_{6} / \mathrm{C}_{3} \mathrm{H}_{8}$ into ionic liquids.

- Screening of several ionic liquids using COSMO-RS for $\mathrm{C}_{3} \mathrm{H}_{6} / \mathrm{C}_{3} \mathrm{H}_{8}$ separation.

- Calculation of excess enthalpy to select the most suitable of silver salt.

\section{A R T I C L E I N F O}

\section{Article history:}

Received 6 August 2012

Received in revised form 24 October 2012

Accepted 14 January 2013

Available online 23 January 2013

\section{Keywords:}

COMOS-RS

Olefin/paraffin gas separation

Silver cations

Ionic liquid

\begin{abstract}
A B S T R A C T
The quantum chemical COSMO-RS method was applied to analyze the equilibrium solubility of gaseous propane and propylene in a set of different room temperature ionic liquids in order to contribute to the design of olefin/paraffin separation technologies based on reactive absorption onto ionic liquids with dissolved silver salts media. First of all, the predictive capability of COSMO-RS was evaluated through a comparison of estimated values with a wide range of solubility experimental data; next a further optimization step based on the comparative analysis of predicted and experimental values of the Henry's law constant of each solute in different ILs was developed to improve the accuracy of the calculations. Afterwards, the optimized COSMO-RS approach was applied to select the most suitable RTILs for $\mathrm{C}_{3} \mathrm{H}_{6} /$ $\mathrm{C}_{3} \mathrm{H}_{8}$ separation based on driving a computational screening of 696 RTILs. Results highlighted that small and symmetric fluorinated inorganic anions such as $\mathrm{PF}_{6}^{-}$or $^{-} \mathrm{BF}_{4}^{-}$provide lower solubilities for both hydrocarbons, but on a whole this results in higher separation selectivities. With regard to the structure of the cation, ILs based on imidazolium, pyridinium and pyrrolidinium cations provide similar properties. However ILs based on monosubstituted butyl ammonium have much lower solubilities for both gases and at the same time higher equilibrium selectivities for propylene. Also it was gathered that less and shorter alkyl chains in the cation also improve the selective separation of these mixtures. Finally, as the separation process is enhanced by the presence of $\mathrm{Ag}^{+}$cations into the ionic liquid, the solubility of 8 commercially available silver salts was qualitatively related to the excess enthalpy of $\mathrm{Ag}^{+}-\mathrm{IL}$ in solution predicted by COSMO-RS in order to select a silver salt suitable to be dissolved in the selected RTIL. Thus, this work reports for the first time the use of a predictive tool in order to facilitate the design of innovative separation processes by reactive absorption in a $\mathrm{Ag}^{+}-\mathrm{IL}_{\mathrm{L}}$ media.
\end{abstract}

(c) 2013 Elsevier B.V. All rights reserved.

\section{Introduction}

Light olefins such as ethylene and propylene are very important to petrochemical industries because they are used as main building blocks for many essential chemicals and products for industrial and domestic applications. Conventional olefin/paraffin separation

\footnotetext{
* Corresponding author. Address: Universidad de Cantabria, Avenida de los Castros s/n, 39005 Santander, Spain. Tel.: +34 942201585; fax: +34 942201591

E-mail address: ortizi@unican.es (I. Ortiz).
}

technologies are based on cryogenic distillation process in columns with 150-200 trays operating at temperatures between 233 and $183 \mathrm{~K}$ and pressures ranging from 16 to 20 bar which lead to high capital investment, operational cost and also negative environmental impact [1-3]. Therefore, it is critical to develop innovative and cost-effective technologies able to separate these streams, overcoming the drawbacks associated to conventional systems. In this sense reactive absorption of olefins using ionic liquids and silver salts has been proposed as a potential alternative to the traditional separation process. The separation process is based on the 


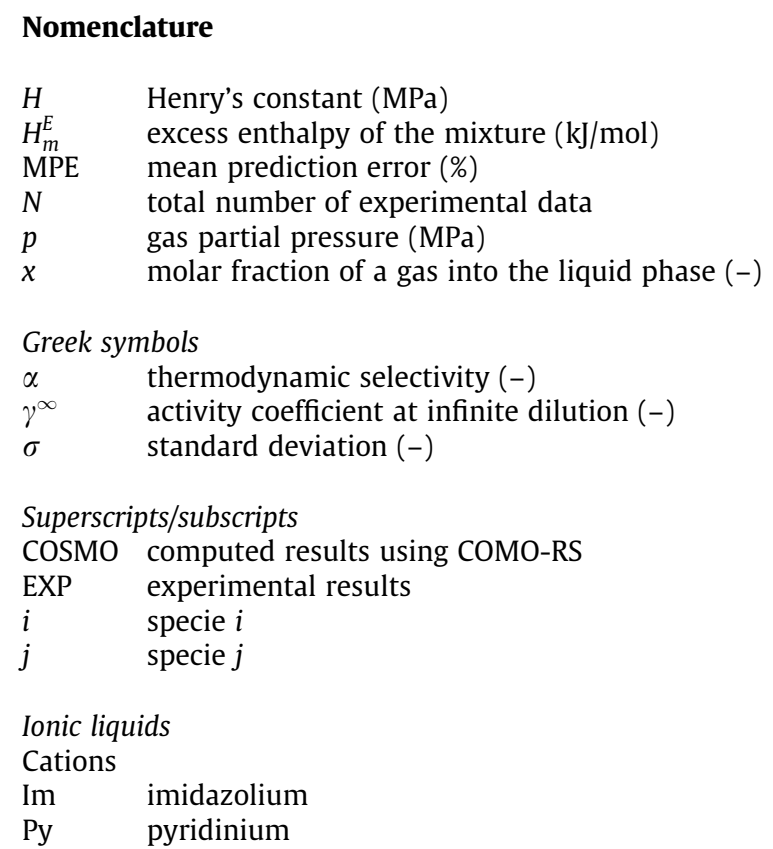

$\begin{array}{ll}\text { Pyr } & \text { pyrrolidinium } \\ \mathrm{N} & \text { ammonium } \\ \mathrm{P} & \text { phosphonium }\end{array}$

Anions

$\mathrm{BF}_{4}^{-} \quad$ tetrafluoroborate

$\mathrm{PF}_{6}^{-} \quad$ hexafluorophosphate

$\mathrm{NO}_{3}^{-} \quad$ nitrate

$\mathrm{Tf}_{2} \mathrm{~N}^{-}$bis-(trifluoromethylsulphonylimide)

$\mathrm{CH}_{3} \mathrm{CO}_{2}^{-}$acetate

$\mathrm{CF}_{3} \mathrm{CO}_{2}^{-}$trifluoroacetate

$\mathrm{CH}_{3} \mathrm{SO}_{3}^{-}$methanesulphonate

$\mathrm{CF}_{3} \mathrm{SO}_{3}^{-}$trifluoromethanesulphonate

$\begin{array}{ll}\text { Alkyl chains } \\ \text { M } & \text { methyl } \\ \text { Pr } & \text { propyl } \\ \text { B } & \text { buthyl } \\ \text { Hx } & \text { hexyl } \\ \text { O } & \text { octyl } \\ \text { D } & \text { decyl } \\ \text { Hexad } & \text { hexadecyl }\end{array}$

ability of silver ions to reversibly react with olefins to form an organometallic complex [4]. The advantage of this chemical complexation is that the formed bonds are stronger than those formed by Van der Waals forces alone, so it is possible to achieve high selectivity and high capacity for the component to be bounded but at the same time, the bonds are still weak enough to be broken by pressure or temperature swings.

Ionic liquids (ILs) are a broad category of organic salts liquid with melting points below $100{ }^{\circ} \mathrm{C}[5,6]$. They usually consist on bulky and asymmetric organic cations such as imidazolium, pyridinium, pyrrolidinium, ammonium and phosphonium combined with a wide range of anions which range from simple halides or small inorganic anions such as tetrafluoroborate and hexafluorophosphate to large organic anions like triflate or bis-trifluoromethylsulphonylimide. Although the physicochemical properties of RTILs are strongly influenced by both their cationic and their anionic moieties, in general ionic liquids show some well-known and remarkable properties which have attracted the attention of many researchers. Some of these interesting physical properties of the ionic liquids that make them interesting as potential solvents are that they present high thermal and chemical stability and remain liquid in a wide range of temperatures, they have a negligible vapor pressure and they are good solvents for a wide range of both inorganic and organic materials [7,8]. Moreover, they have been termed as "designer solvents" as their properties can be tuned by a suitable combination of the ionic moieties.

Several authors have reported [9-16] the viability to carry out the separation of olefin/paraffin mixtures by reactive absorption in $\mathrm{Ag}^{+}$-RTIL medium. These works included kinetic and thermodynamic data of the complexation reaction between propylene and silver cations remarking the solvent potential improvement of the ionic liquid compared to aqueous solutions. It was proved that the total absorption of propylene was the sum of the physical solubility and the chemical complexation effects. Nevertheless, for propane the only absorption is due to physical solubility, even when silver cations are dissolved in the ionic liquid. Therefore in order to enhance the separation performance it is desirable to find an ionic liquid with low affinity for propane and at the same time, able to dissolve a suitable silver salt. Recently, a new strategy to synthesize novel ionic liquids whose cations consist of $\mathrm{Ag}^{+} \mathrm{com}-$ plexes was introduced. The neutral organic ligands complexed to $\mathrm{Ag}^{+}$can be olefins, amines, or amides. It has been demonstrated that Ag-olefin and Ag-amide complex-based ionic liquids show remarkable olefin/paraffin permselectivity [17-21].

Although in recent years a steeply growing amount of experimental solubility data has been published in this field [22], the huge amount of ionic liquids that can be synthesized suggest the need of a tool to estimate the equilibrium solubility of a gas in different ionic liquids.

Several methods have been reported to predict the thermodynamic behavior of different compounds in ionic liquids ranging from molecular dynamics (MD) using atomistic force fields, over quantitative structure-property relationship (QSPR) models, to classical thermodynamic models, such as NRTL, UNIQUAC or UNIFAC $[23,24]$. The main drawback is that most of the parameters of these models must be determined from a large amount of experimental data, which is not available for the vast majority of ionic liquids [25]. On the contrary, the quantum chemistry based of the "conductor-like screening model for real solvents" (COSMORS) method has a small and general parameter set that does not need to be adjusted to specific ILs and therefore it can be applied in a predictive way to the full range of ILs [24]. The COSMO-RS calculations are based on a unique combination of a quantum chemical treatment of solutes and solvents with an efficient statistical thermodynamics procedure for the molecular surface interactions which finally enables the efficient calculation of many properties that other methods can barely predict. Thus, in this sense COSMO-RS approach is a unique a priori computational tool which can be applied to predict the equilibrium solubility of a gas in a given ionic liquid based on the structural information of the compounds [26-30].

The main objective o this work is to develop a predictive procedure that selects the optimum ionic liquid and silver salt to carry out the separation of olefin/paraffin gas mixtures by reactive absorption using $\mathrm{Ag}^{+}$-ILs as absorption media. For this purpose the COSMO-RS methodology has been applied to predict the 

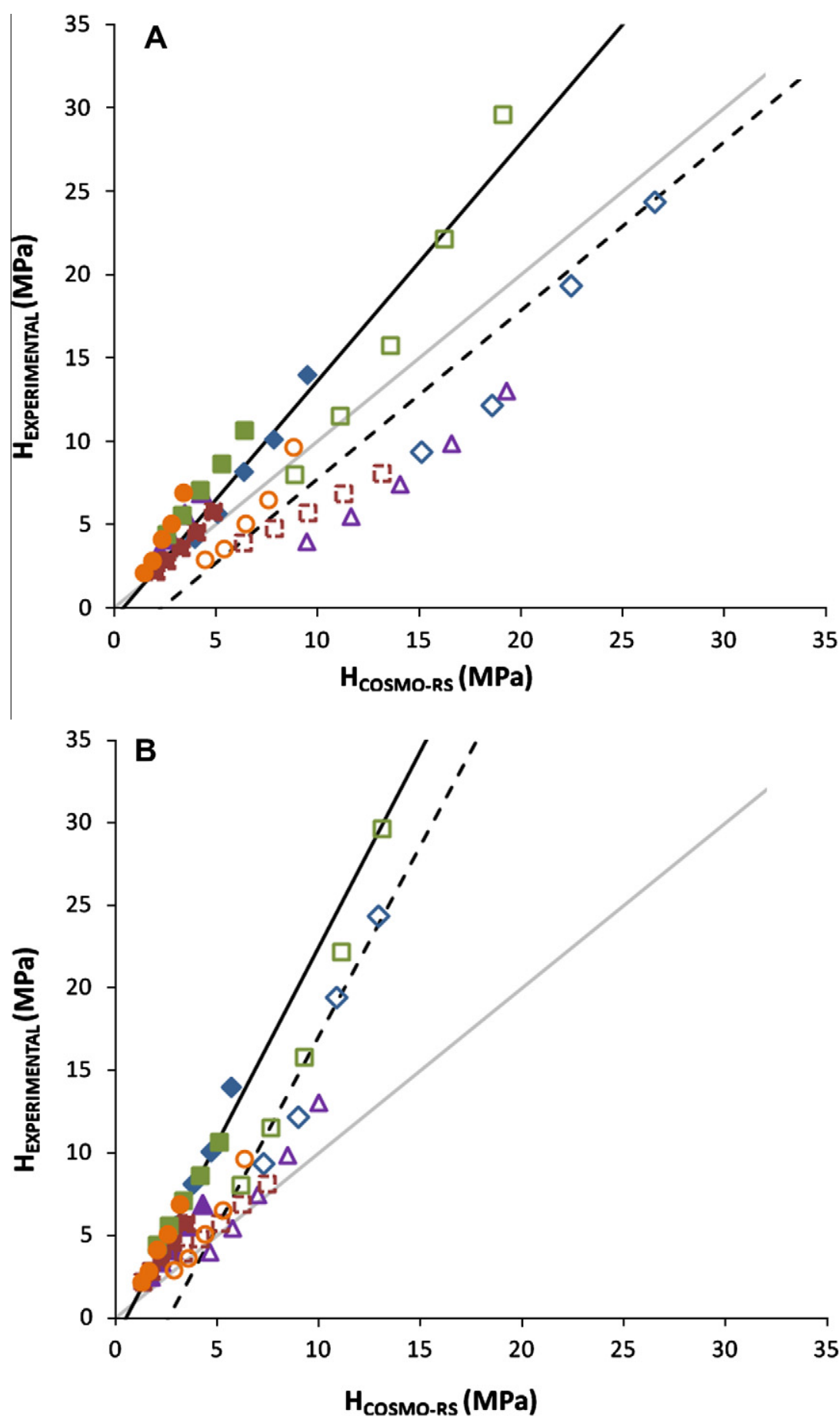

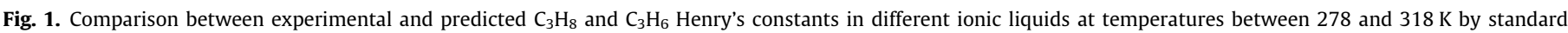

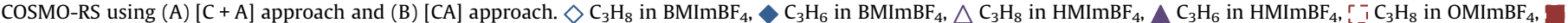

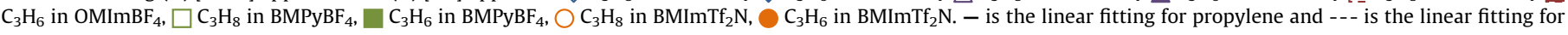
propane.

physical solubility and thermodynamic selectivity of propane and propylene in different ionic liquids. A computational screening of 696 ionic liquids was carried out, considering different structures by varying the types of anions and cations and also the number and length of radical substituents of the cation. In addition, a qualitative study of the solubility of 8 commercially available silver salts into ionic liquids that contain the same anion was performed in order to select the most suitable silver salt.

\section{Computational details}

In this work, the COSMO-RS calculations were carried out following a multistep procedure. First, the software Gaussian03 was used for the quantum-chemical calculation [31] to generate the COSMO files for each compound studied. For this purpose, the molecular geometries of the gaseous solutes and the ILs were optimized at the B3LYP/6-31++G** computational level, while the 
Table 1

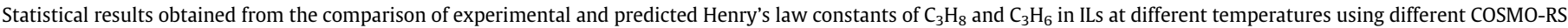
computational approaches.

\begin{tabular}{|c|c|c|c|c|c|c|c|}
\hline Model & Method & Compound & Slope & $y$-Intercept & $R^{2}$ & $\Sigma$ & MPE (\%) \\
\hline \multirow[t]{4}{*}{ COSMO-RS } & \multirow[t]{2}{*}[C+A]{} & $\mathrm{C}_{3} \mathrm{H}_{8}$ & 1.01 & -2.37 & 0.66 & 0.59 & 47.4 \\
\hline & & $\mathrm{C}_{3} \mathrm{H}_{6}$ & 1.43 & -0.61 & 0.85 & 0.29 & 23.6 \\
\hline & \multirow[t]{2}{*}[\mathrm{CA}]{} & $\mathrm{C}_{3} \mathrm{H}_{8}$ & 2.31 & -6.05 & 0.90 & 0.31 & 24.4 \\
\hline & & $\mathrm{C}_{3} \mathrm{H}_{6}$ & 2.37 & -1.24 & 0.93 & 0.48 & 45.9 \\
\hline \multirow[t]{4}{*}{ Optimized COSMO-RS } & \multirow[t]{2}{*}[C+A]{} & $\mathrm{C}_{3} \mathrm{H}_{8}$ & 0.76 & 2.07 & 0.66 & 0.37 & 30.9 \\
\hline & & $\mathrm{C}_{3} \mathrm{H}_{6}$ & 0.93 & 0.64 & 0.81 & 0.25 & 21.3 \\
\hline & \multirow[t]{2}{*}[\mathrm{CA}]{} & $\mathrm{C}_{3} \mathrm{H}_{8}$ & 0.80 & 1.60 & 0.90 & 0.31 & 22.9 \\
\hline & & $\mathrm{C}_{3} \mathrm{H}_{6}$ & 1.00 & 0.00 & 0.93 & 0.15 & 11.6 \\
\hline
\end{tabular}

molecular geometries of the silver salts were optimized at the B3LYP/DGDZVP computational level. The molecular geometry optimization of every compound was performed considering a gas phase environment. In each case, vibrational frequency calculations were checked to confirm the presence of an energy minimum state. Two different molecular models, $[\mathrm{C}+\mathrm{A}]$ and $[\mathrm{CA}]$, were considered to simulate IL solvents in COSMO-RS calculations, that consider the ionic liquid as independent counterions, $[C+A]$, and ion-paired structures, [CA], respectively. To perform the molecular model of independent counterions in COSMO-RS calculations, ILs were treated as an equimolar mixture of cations and anions. The COSMO files include the ideal screening charges on the molecular surface of each species, calculated by the COSMO continuum solvation model using theory level BVP86/TZVP/DGA1. Subsequently, COSMO files were used as an input in the COSMOthermX [32] code to calculate the Henry's law constant of propane and propylene in and excess enthalpies of silver cations in different ILs. Henry's law constants were estimated attending to the expression:

$H_{i}=\gamma^{\infty} \cdot p_{i}$

where $\gamma^{\infty}$ is the activity coefficient of the propane or propene solute in the IL at infinite dilution and $P_{i}$ is the vapor pressure of pure propane or propene at the studied temperature. According to this chosen quantum method, the functional, and the basis set, we used the corresponding parametrization (BP_TZVP_C21_0111) that is required for the calculation of physicochemical data and contains intrinsic parameters of COSMOtherm, as well as specific parameters.

The errors in the Henry's constants of both hydrocarbons in the different ionic liquids calculated using the implemented COSMORS approach against experimental data previously obtained were determined by calculating the mean prediction error (MPE) and the standard deviation (Eqs. (2) and (3)):

$\mathrm{MPE}=\frac{1}{N} \sum_{1}^{N} \frac{\left|H_{\mathrm{EXP}}-H_{\mathrm{COSMO}}\right|}{H_{\mathrm{EXP}}} * 100$

$\sigma=\sqrt{\frac{\sum_{i=1}^{n}\left(\frac{H_{\mathrm{EXP}}-H_{\mathrm{COSMO}}}{H_{\mathrm{EXP}}}\right)^{2}}{\mathrm{~N}-1}}$

where $N$ is the total number of data used, $H_{\text {COsmo }}$ is the Henry's constant of propane or propylene obtained by COSMO and $H_{\text {EXP }}$ is the corresponding value experimentally determined.

\section{Results}

3.1. Optimization of COSMO-RS approach to predict the $\mathrm{C}_{3} \mathrm{H}_{8}$ and $\mathrm{C}_{3} \mathrm{H}_{6}$ solubility in ionic liquids

In previous works carried out by our research group it was experimentally observed that the solubility of propane and propylene in different silver-free ionic liquids exhibit an ideal behavior. Hence the physical solubility of the individual gas component at moderate pressures can be described by the Henry's law (Eq. (4)).

$H_{i}=\frac{p_{i}}{x_{i}}$

where $H_{i}$ is the Henry's constant, $P_{i}$ is the partial pressure of the gas and $x_{i}$ is the molar fraction of the gas in the ionic liquid.

Thus, assuming an ideal behavior of these mixtures the equilibrium selectivity $\left(\alpha_{i} / j\right)$ can be determined as the ratio between the Henry's constant of each gas in the ionic liquid (Eq. (5)).

$\alpha_{i / j}=\frac{H_{j}}{H_{i}}$

In order to evaluate the capability of COSMO-RS to predict the Henry's law constants of propane and propylene in the different ionic liquids, the Henry's constants predicted by COSMO-RS were compared against a set of experimental data previously reported $[9,10]$. The comparison included values of the Henry's constants of both propane and propylene in different ionic liquids varying the nature of the cation, the alkyl chain length of the cation and the anion at temperatures in the range of $278-318 \mathrm{~K}$ (Fig. 1A and B).

The linear regressions obtained between experimental and computed $H$ data (Eqs. (6) and (7)) suggest the capability of the COSMO-RS approach to predict qualitatively the trend of the Henry's constants of propane and propylene in ionic liquids. However in order to calculate the solubility of both hydrocarbons in different ionic liquids more accurately the computational method was improved by calibrating against a limited set of experimental data (Fig. $1 \mathrm{~A}$ and $\mathrm{B}$ ).

Fig. $1 \mathrm{~A}$ and $\mathrm{B}$ shows that although the COSMO-RS approach is suitable to predict general trends in the solubility of propane and propylene in ionic liquids it is not accurate enough to predict quantitative values of the Henry's constants. Moreover, in the comparison between experimental and calculated data the slopes of the linear regression fittings for both methods, [CA] (Eqs. (6) and (7)) and $[\mathrm{C}+\mathrm{A}]$ (Eqs. (8) and (9)) show a systematic underestimation of the Henry's constant of both gases.

$H_{\mathrm{C}_{3} \mathrm{H}_{8}, \text { EXPERIMENTAL }}=2.31 * H_{\mathrm{C}_{3} \mathrm{H}_{8}, \text { COSMO }[\mathrm{CA}]}-6.05$

$H_{\mathrm{C}_{3} \mathrm{H}_{6}, \text { EXPERIMENTAL }}=2.37 * H_{\mathrm{C}_{3} \mathrm{H}_{6}, \text { COSMO }[\mathrm{CA}]}-1.24$

$H_{\mathrm{C}_{3} \mathrm{H}_{8}, \text { EXPERIMENTAL }}=1.01 * H_{\mathrm{C}_{3} \mathrm{H}_{8}, \text { COSMO }[\mathrm{C}+\mathrm{A}]}-2.37$

$H_{\mathrm{C}_{3} \mathrm{H}_{6}, \text { EXPERIMENTAL }}=1.43 * H_{\mathrm{C}_{3} \mathrm{H}_{6}, \text { COSMO }[\mathrm{C}+\mathrm{A}]}-0.61$

The statistical analysis for the $[\mathrm{C}+\mathrm{A}]$ and $[\mathrm{CA}]$ models before and after the optimization are compiled in Table 1.

This difference between calculated and experimental data was corrected using the linear fittings shown in Eqs. (6)-(9), and therefore an optimization of the methodology was carried out providing 

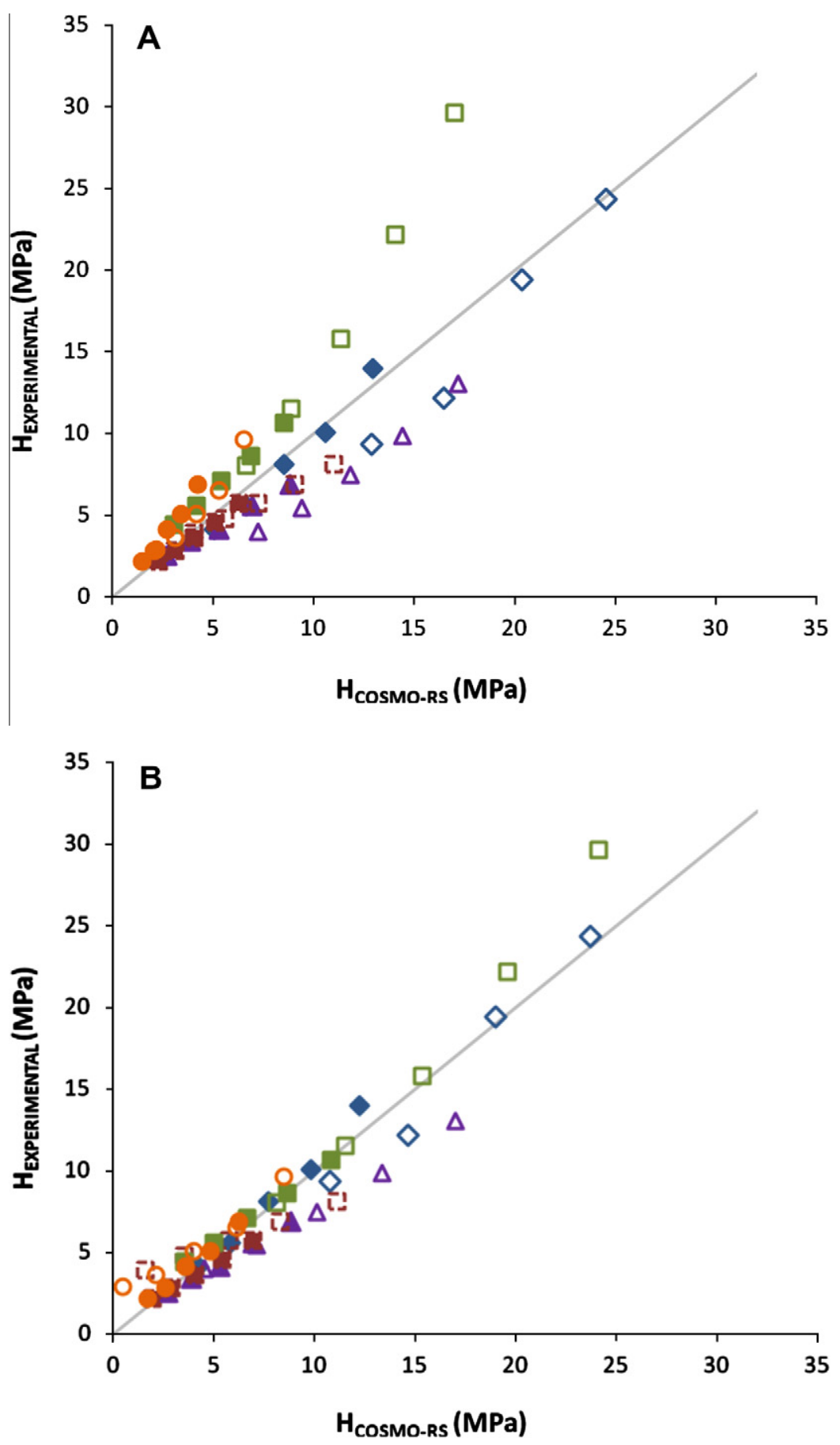

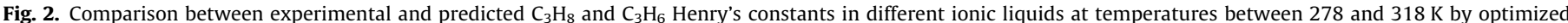

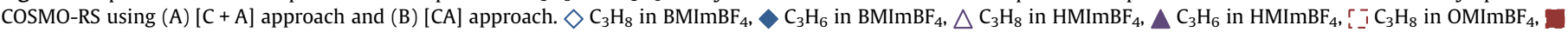

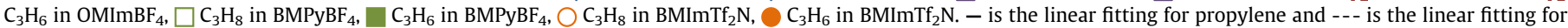
propane.

an enhanced tool for the estimation of the propane and propylene solubility in any ionic liquid. The results plotted in Fig. $2 \mathrm{~A}$ and $\mathrm{B}$ shows that although the optimized $[C+A]$ model is suitable to predict the trend in the solubility of propane and propylene in different ionic liquids, the [CA] model generally provides higher accuracy in the quantitative prediction of $H$ coefficients in ILs (MPE $<22.9 \%$ ); thus proving the potential of the optimized COSMO-RS methodology developed in this work to predict accurately the solubility of propane and propylene in different ionic liquids with imidazolium and pyridinium cations.
It must be highlighted that the major error source in this study corresponds to the Henry's constant values obtained at higher temperatures, near $318 \mathrm{~K}$, where the solubility of both hydrocarbons is very low. This is in agreement with the results previously obtained by Palomar et al. [30] where they observed that although four different COSMO-RS computational approaches were able to provide a qualitative description of the solubility-temperature trend of $\mathrm{CO}_{2}$ in the ionic liquid $\mathrm{HMImTf}_{2} \mathrm{~N}$ in the 283.1-343.1 $\mathrm{K}$ temperature range, the COSMO-RS methodology was not suitable to carry out a quantitative analysis of the $\mathrm{CO}_{2}$ solubility at different temperatures. 
Table 2

Molecular structures of the cations and anions studied in this work.

CATIONS

\begin{tabular}{|ll|}
\hline ANIONS & \\
\hline Tetrafluoroborate $\left(\mathrm{BF}_{4}{ }^{-}\right)$ & Acetate $\left(\mathrm{CH}_{3} \mathrm{CO}_{2}{ }^{-}\right)$ \\
$\mathrm{BF}_{4}^{\ominus}$ & $\mathrm{CH}_{3} \mathrm{CO}_{2}^{\ominus}$ \\
Hexafluorophosphate $\left(\mathrm{PF}_{6}{ }^{-}\right)$ & Trifluoroacetate $\left(\mathrm{CF}_{3} \mathrm{CO}_{2}{ }^{-}\right)$ \\
$\mathrm{PF}_{6}^{\ominus}$ & $\mathrm{CF}_{3} \mathrm{CO}_{2}^{\ominus}$ \\
Bis-trifluoromethylsulphonylimide $\left(\mathrm{Tf}_{2} \mathrm{~N}^{-}\right)$ & Methanesulphonate $\left(\mathrm{CH}_{3} \mathrm{SO}_{3}{ }^{-}\right)$ \\
$\left(\mathrm{CF}_{3} \mathrm{SO}_{2}\right)_{2} \mathrm{~N}^{\ominus}$ & $\mathrm{CH}_{3} \mathrm{SO}_{3}^{\ominus}$ \\
Nitrate $\left(\mathrm{NO}_{3}{ }^{-}\right)$ & Trifluoromethanesulphonate $\left(\mathrm{CF}_{3} \mathrm{SO}_{3}{ }^{-}\right)$ \\
$\mathrm{NO}_{3}^{\ominus}$ & $\mathrm{CF}_{3} \mathrm{SO}_{3}^{\ominus}$ \\
\hline
\end{tabular}

The obtained results show the $[\mathrm{C}+\mathrm{A}]$ approach can predict the trend in the solubility of both gases into ionic liquids. Moreover, the optimized COSMO-RS methodology using the [CA] method predicts experimental results accurately allowing carrying out a quantitative analysis. Therefore the best way to proceed would result from a first screening of a large number of ILs using the [C $+\mathrm{A}]$ method in order to select those ILs having better performance for olefin/paraffin separation, and afterwards applying the [CA] method, that involves more tedious calculations to achieve a higher accuracy in the solubility results.

\subsection{Physical solubility of $\mathrm{C}_{3} \mathrm{H}_{8}$ and $\mathrm{C}_{3} \mathrm{H}_{6}$ in RTILs}

Once it has been developed the optimized COSMO-RS approach useful to evaluate the gas solubility of propane and propylene in different ionic liquids, the main objective of this work is to apply this methodology as a tool to select the most suitable ionic liquid for the selective separation of propane/propylene gas streams. In order to minimize the preliminary experimental effort to be performed, a computational screening using COSMO-RS and the $[C+A]$ model was carried out for 696 ionic liquids based on different cations (imidazolium, pyridinium, pyrrolodinium, ammonium and phosphonium) and anions $\left(\mathrm{BF}_{4}^{-}, \mathrm{PF}_{6}^{-}, \mathrm{NO}_{3}^{-}, \mathrm{Tf}_{2} \mathrm{~N}^{-}\right.$, $\left.\mathrm{CH}_{3} \mathrm{CO}_{2}^{-}, \mathrm{CF}_{3} \mathrm{CO}_{2}^{-}, \mathrm{CH}_{3} \mathrm{SO}_{3}^{-}, \mathrm{CF}_{3} \mathrm{SO}_{3}^{-}\right)$. Table 2 compiles the cation and anion structures of the ionic liquids studied in this work.

Figs. 3 and 4 show the calculated solubility (as Henry's constant) of propane and propylene respectively in some of the most common ionic liquids. In general the solubility of propane and propylene follow the same trend according to the changes in the molecular structure of the ionic liquid. However, the physical selectivity increases as the solubility of both gases decreases (Fig. 5). These results are in good agreement with previous results obtained by Palomar et al. [25] working with $\mathrm{CO}_{2}$ and $\mathrm{N}_{2}$.

These results point to the important role that the structure of both, the anion and also the cation moieties of the ionic liquid play on the physical solubility of both hydrocarbons as well as on the separation selectivity. Generally, anions with more electron donor character, as $\mathrm{CH}_{3} \mathrm{CO}_{2}^{-}$or $\mathrm{CH}_{3} \mathrm{SO}_{3}^{-}$, present higher solubilities for propylene and also for propane but at the same time lower selectivities. On the other hand, big anions with disperse charge like $\mathrm{BF}_{4}^{-}$or $\mathrm{PF}_{6}^{-}$result in lower solubilities and higher physical selectivities.

Figs. 3-5 also highlights the importance of the structure of the cation in the physical solubility of both hydrocarbons and also in the thermodynamic selectivity. In order to study in more depth this influence, further studies were carried out analyzing the influence of the nature of the cation, the alkyl chain length and the number of substituents in the cation.

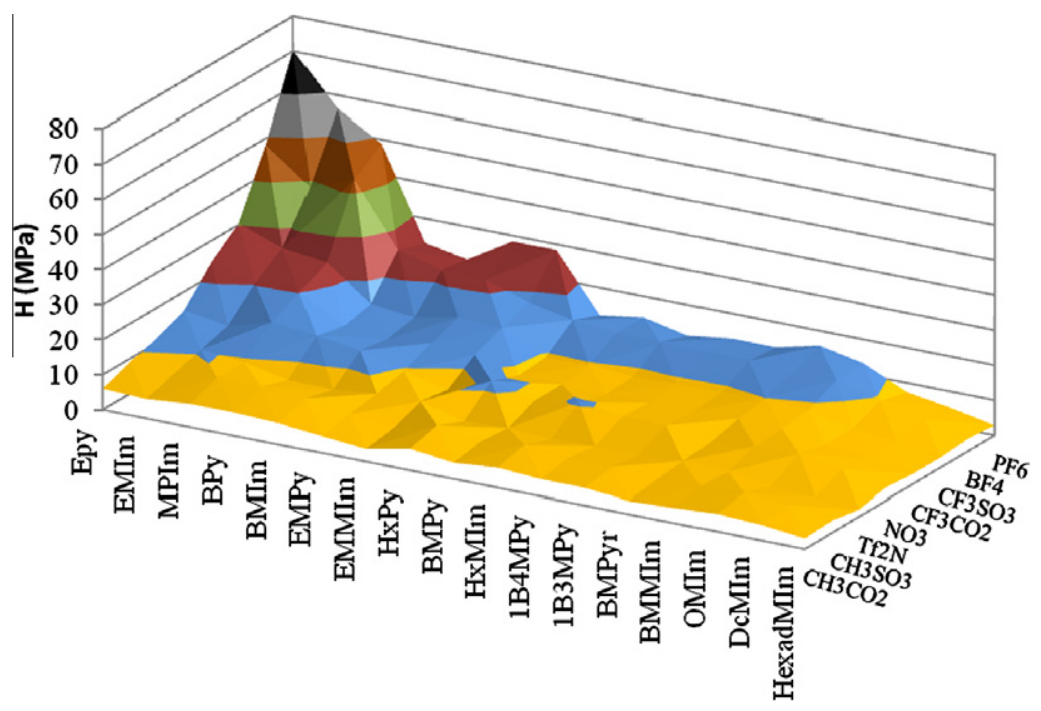

Fig. 3. Screening of $\mathrm{C}_{3} \mathrm{H}_{8}$ solubility in the most common ionic liquids at $T=298.15 \mathrm{~K}$ calculated by optimized COSMO-RS approach 


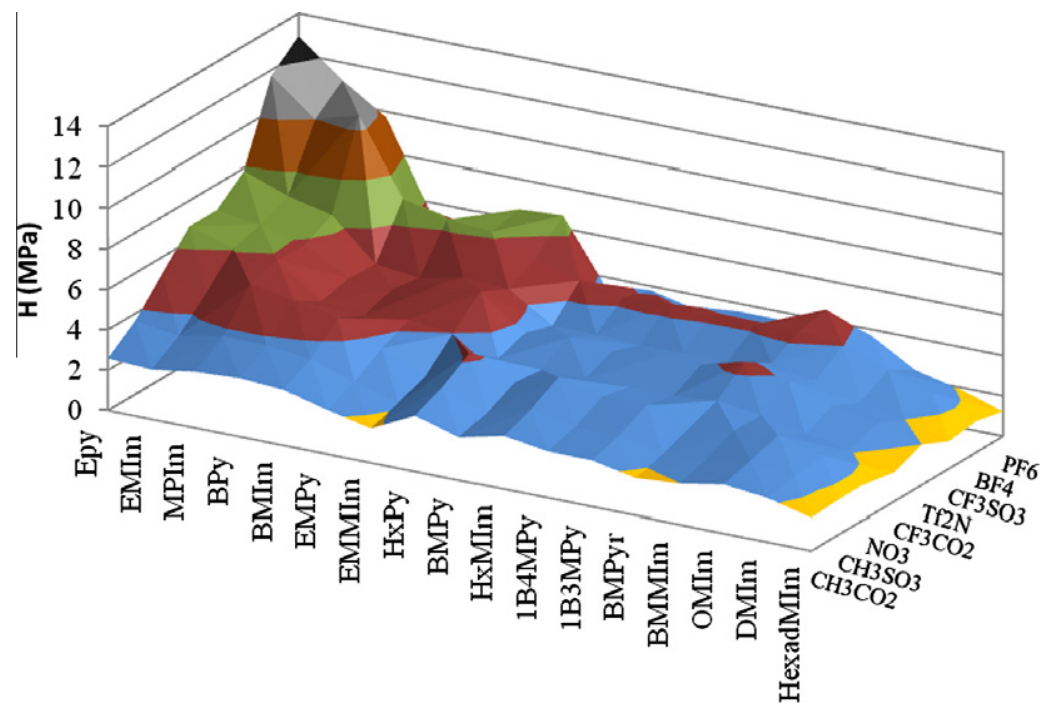

Fig. 4. Screening of $\mathrm{C}_{3} \mathrm{H}_{6}$ solubility in the most common ionic liquids at $T=298.15 \mathrm{~K}$ calculated by optimized COSMO-RS approach.

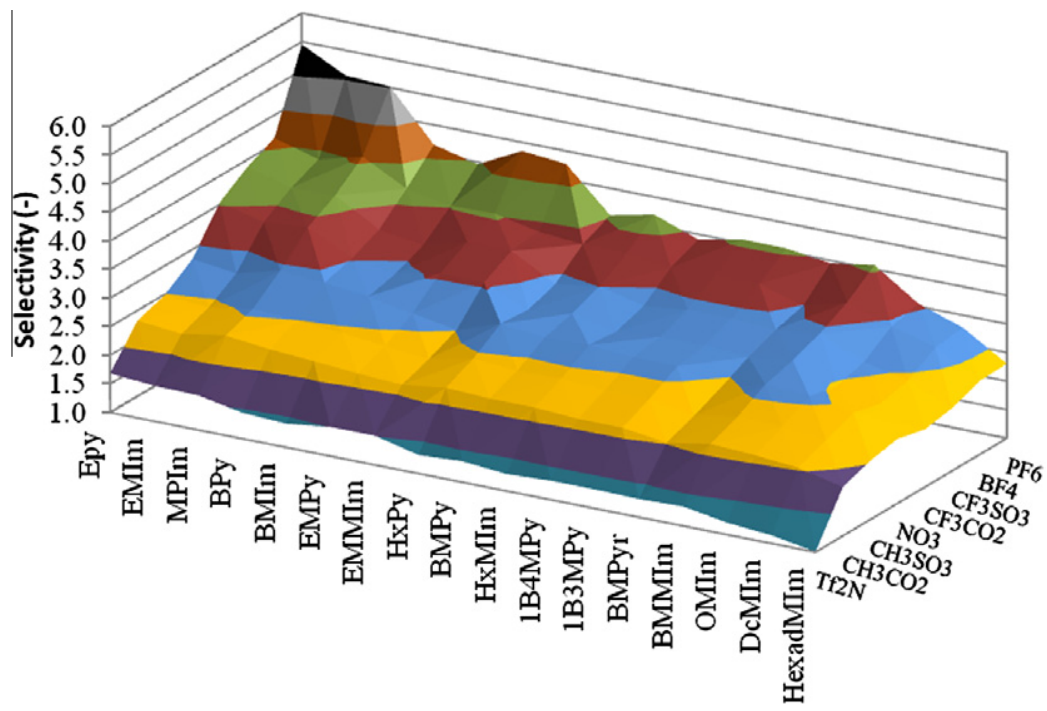

Fig. 5. Screening of $\mathrm{C}_{3} \mathrm{H}_{6} / \mathrm{C}_{3} \mathrm{H}_{8}$ selectivity in some of the most common ionic liquids at $T=298.15 \mathrm{~K}$ calculated by optimized COSMO-RS approach.

Fig. 6 shows the influence of the alkyl chain length of the ionic liquid in the range from 1 to 10 carbon atoms for the 1-methylimidazolium tetrafluoroborate family. The highest solubility of both gases was obtained for the cation with the longest alkyl chain (C10) because increasing the number of carbon atoms of aliphatic substituent provides more organic character to the ionic liquid, showing more affinity for both hydrocarbons. Once more, the selectivity follows the opposite trend, increasing from 0.7 to 4.5 when the radical chain length was reduced from $\mathrm{C} 10$ to $\mathrm{C} 1$.

Fig. 7 shows the influence of the number of substituents in the cation on the gas solubility. They were analyzed both the solubility of propane and propylene as well as the separation selectivity as a function of the number of methyl groups introduced in the cation structure in the 1-ethyl imidazolium tetrafluoroborate family $\left(\mathrm{EImBF}_{4}\right)$. The results show that the solubility of propane and propylene slightly decreased when the number of methyl groups was reduced from 2 to 1 ; however the solubility was almost 7 times lower for propane and 4.6 times lower for propylene when the number of methyl substituents in the cation decreased from 1 to
0 . At the same time the separation selectivity is increased from 2.6 for $\mathrm{EMMImBF}_{4}$ to 5.1 using $\mathrm{EImBF}_{4}$.

The last variable in the ionic liquid structure under study is the type of cation. In this work 5 different types of the most common cations (ammonium, pyridinium, pyrrolidinium, imidazolium and phosphonium) were analyzed. Fig. 8 plots the calculated solubility of propane and propylene and the separation selectivity as a function of the type of cation of the ionic liquid at $298.15 \mathrm{~K}$ with tetrafluoroborate anion in all cases. Fig. 8 shows a strong dependence between the gas solubility and the nature of the cation. The highest solubility is obtained with phosphonium-based ionic liquids. This is because commonly phosphonium-based ionic liquids has several and long substituents which provide high affinity for both hydrocarbons, leading at the same time to the lowest separation selectivity (2.3). On the other hand imidazolium, pyridinium and pyrrolidinium-based ionic liquids provide similar results, with lower gas solubilities and separation selectivity around 3. This comparable behavior can be attributed to the similar structure of these 3 cations. However imidazolium-based ionic liquids gener- 


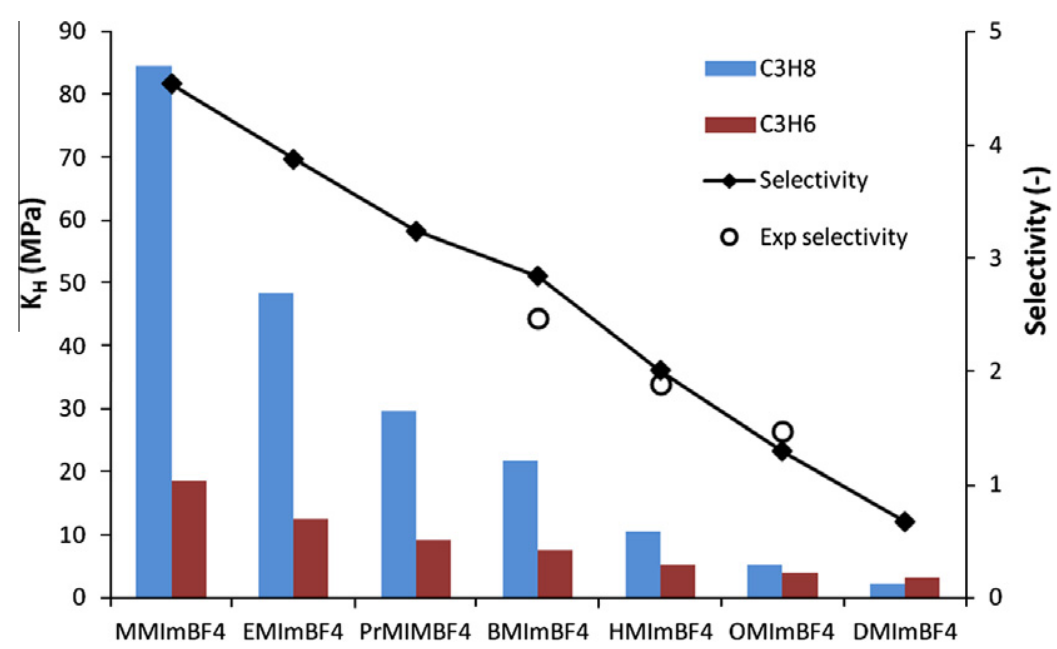

Fig. 6. Effect of the length of the alkyl chain of the ionic liquid cation on the solubility of $\mathrm{C}_{3} \mathrm{H}_{8}$ and $\mathrm{C}_{3} \mathrm{H}_{6}$ and separation selectivity.

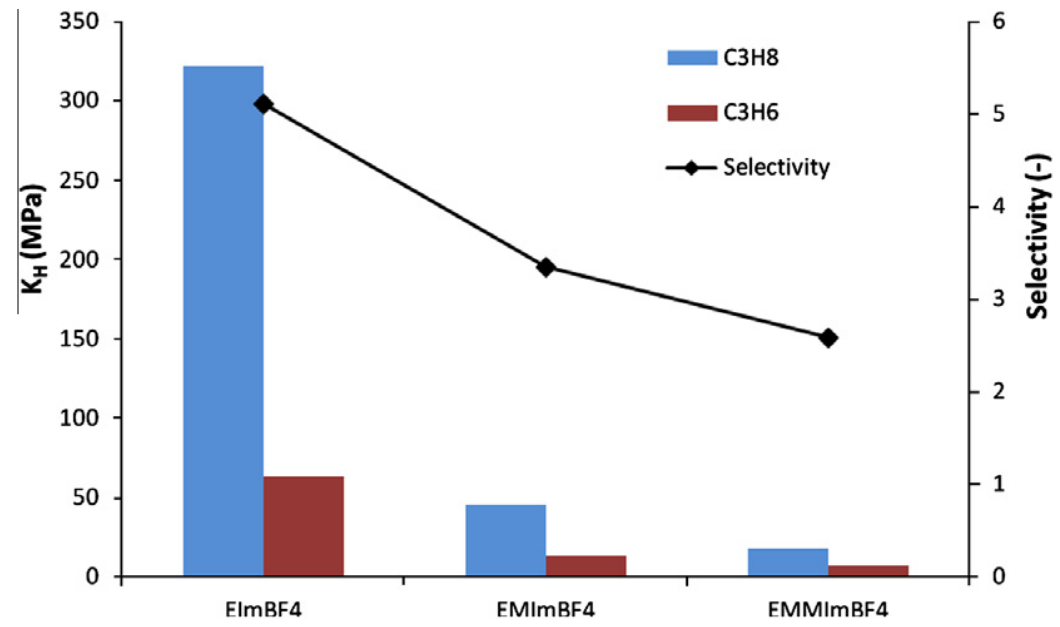

Fig. 7. Effect of the number of substituents of the ionic liquid cation in the solubility of $\mathrm{C}_{3} \mathrm{H}_{8}$ and $\mathrm{C}_{3} \mathrm{H}_{6}$ and selectivity.

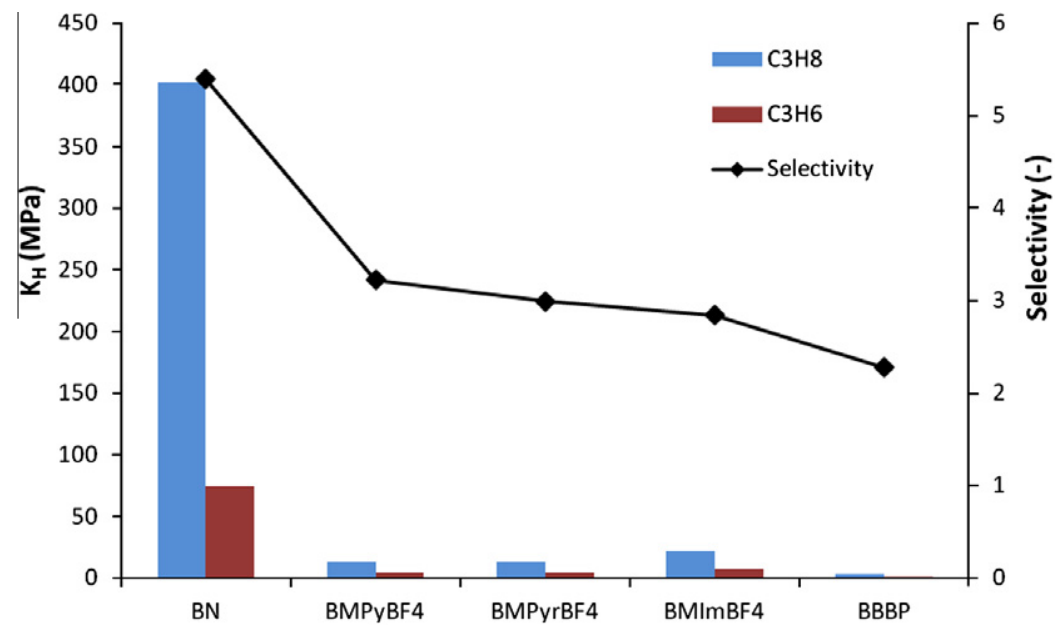

Fig. 8. Effect of the nature of the cation in the solubility of $\mathrm{C}_{3} \mathrm{H}_{8}$ and $\mathrm{C}_{3} \mathrm{H}_{6}$ and selectivity.

ally have the lowest viscosities of these three families, leading to a better performance in the gas absorption process where the mass transfer in the liquid side is often the controlling step. On the other hand, ionic liquids based on monosubstituted butyl ammonium $\left(\mathrm{BN}^{+}\right)$cation provide the lowest affinity for both gases due to the presence of the polar acidic hydrogen groups linked to nitrogen, which must decrease the affinity of ILs for non-polar hydrocarbons such as $\mathrm{C}_{3} \mathrm{H}_{6}$ and $\mathrm{C}_{3} \mathrm{H}_{8}$ leading to the highest physical selectivity between propane and propylene ( 5,4 for the ionic liquid buthylammonium tetrafluoroborate). 


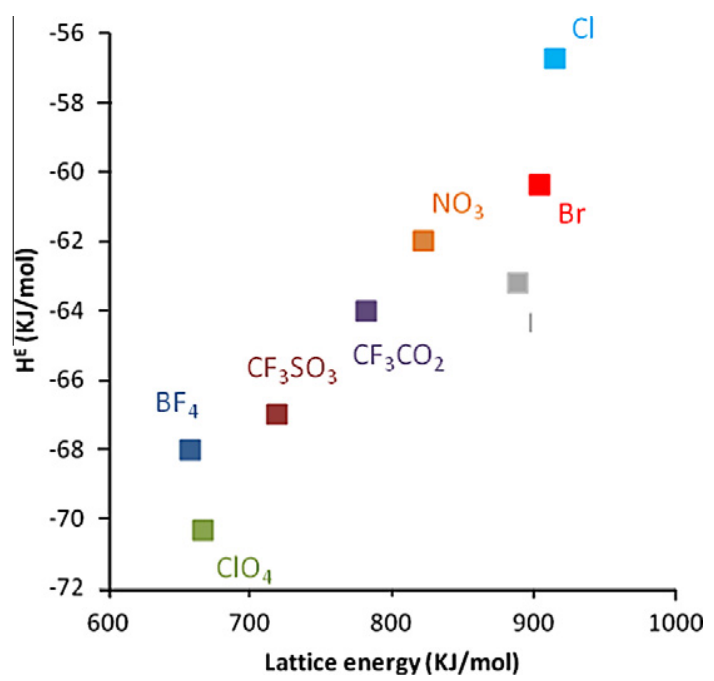

Fig. 9. Comparison of the lattice energy of 8 commercially available silver salts with the excess molar enthalpies of $\mathrm{Ag}^{+}$-ILs mixtures at $T=298.15 \mathrm{~K}$, calculated by the COSMO-RS/[CA] computational approach.

\subsection{Qualitative silver salt solubility in RTILS}

Since the absorption of propylene in a given ionic liquid is enhanced by the addition of a silver salt, it is crucial to find out the most suitable silver salt to be dissolved in a specific ionic liquid. Due to the huge amount of combinations between silver salts and ionic liquids it is interesting to develop a computational approach able to predict a qualitative trend in the solubility of different silver salts.

In previous works Palomar et al. found out that gas-liquid [25,29,30], liquid-liquid [33] and solid-liquid [34] equilibrium data for favorable separation processes based on IL solvents were associated to a higher exothermicity of the mixing process. This methodology was applied in this case to analyze the solubility of different silver salts in a certain ionic liquid containing the same anion. Fig. 9 shows the relationship between the lattice energy of 8 commercially available silver salts reported in literature [35] and the calculated $H_{m}^{E}$ values for the BMIm cation family containing the same anion as the silver salt under study.

It can be seen that there exists a relationship between the lattice energy and the excess enthalpy of the $\mathrm{Ag}^{+}$-ILs mixture. This trend is in good agreement with the previous knowledge about the behavior of silver salts solutions. It is well known that silver halides have a negligible solubility. Also previous studies reveal that although silver nitrate is very soluble in water, it is not easily dissolved in ionic liquids like $\mathrm{BMImNO}_{3}$. On the other hand $\mathrm{AgBF}_{4}$, which has the lowest lattice energy, can be dissolved in different ionic liquids containing the $\mathrm{BF}_{4}^{-}$anion such as $\mathrm{BMImBF}_{4}$ or $\mathrm{BMPyBF}_{4}$. This trend is in good agreement with the previous knowledge about the behavior of silver salt solutions. It is well known that silver halides have a negligible solubility in ILs. Previous studies also reveal that silver nitrate is not so easy to dissolve in IL, such as $\mathrm{BMImNO}_{3}$, as in water. On the other hand $\mathrm{AgBF}_{4}$, which has the lowest lattice energy, is soluble in different ionic liquids containing the $\mathrm{BF}_{4}^{-}$anion such as $\mathrm{BMImBF}_{4}$ or $\mathrm{BMPyBF}_{4}$. COSMO-RS method anticipates that silver salts with $\mathrm{PF}_{6}^{-}$and $\mathrm{ClO}_{4}^{-}$should also present high solubility in ILs with common anion.

\section{Conclusions}

This work presents for the first time the use of a predictive tool COSMO-RS to facilitate the design of reactive absorption processes.
In this case the COSMO-RS methodology was applied to select the most effective ionic liquid-silver salt system to carry out the separation of olefin/paraffin gas mixtures by reactive absorption.

A general evaluation of the capability of COSMO-RS to predict the Henry's law constants of propane and propylene in ILs was performed by the comparison of the computed results with a set of experimental solubility data in different ionic liquids between 278-318 K. Results proved the capability of the computational approach to provide qualitative predictions of the solubility trends of both hydrocarbons in ILs, although suggesting an overestimation of the predicted values in comparison to the experimental ones. Therefore, the experimental-calculated correlations obtained by linear regression fitting of the data were applied to correct the computed Henry's law constants of gaseous solutes in order to obtain a more accurate estimation of the propane and propylene solubility. In most cases the solubility of propane and propylene follow the same trend according to the changes in the structure of the ionic liquid. Therefore, since the absorption of olefins can be greatly enhanced by the addition of silver cations the best ionic liquid to perform the separation process is the one which shows the lowest propane solubility and at the same time is suitable to dissolve a silver salt. Concerning the anion selection, smaller symmetric anions such as $\mathrm{BF}_{4}^{-}$provide the lowest solubility of both hydrocarbons and also the highest thermodynamic selectivity. Regarding the structure of the cation, ionic liquids based on imidazolium, pyridinium and pyrrolidinium presented a similar behavior in terms of physical solubility and selectivity. However, we recommend the use of imidazolium-based ionic liquids since on the whole they have the lowest viscosities of these three families, leading to a better performance in gas absorption processes where the mass transfer in the liquid side is the controlling step. Ammonium-based ionic liquids showed the lowest physical solubility and also the highest thermodynamic selectivity, thus pointing this group as another cation family to be taken into consideration for olefin/paraffin separation purposes. Additionally, based upon the excess enthalpy calculations and the lattice energy of 8 commercially available silver salts it was found that $\mathrm{AgBF}_{4}$ seems to be the most suitable silver salt to be dissolved in ionic liquids containing the same anion. Thus, based upon computational results it can be concluded that the most suitable system to carry out the separation of propane/propylene gas mixtures by reactive absorption should be based on an ionic liquid with the $\mathrm{BF}_{4}^{-}$anion and an ammonium or imidazolium-based cation with the less number of methyl groups as possible and silver tetrafluoroborate $\left(\mathrm{AgBF}_{4}\right)$ as a silver salt.

\section{Acknowledgements}

This research has been funded by the Spanish Ministry of Science and Innovation (Project CTQ2008-00690/PPQ). Marcos Fallanza also thanks MICINN for the FPI fellowship. Authors are also very grateful to "Centro de Computación Científica de la Universidad Autónoma de Madrid" for the computational facilities.

\section{Appendix A. Supplementary material}

Supplementary data associated with this article can be found, in the online version, at http://dx.doi.org/10.1016/j.cej.2013.01.052.

\section{References}

[1] D.J. Safarik, R.B. Eldridge, Olefin/paraffin separations by reactive absorption: a review, Industrial and Engineering Chemistry Research 37 (1998) 2571-2581.

[2] P. Chilukuri, K. Rademakers, K. Nymeijer, L. Van Der Ham, H.D. Van Berg Propylene/propane separation with a gas/liquid membrane contactor using a silver salt solution, Industrial and Engineering Chemistry Research 46 (2007) 8701-8709. 
[3] T.A. Reine, R.B. Eldridge, Absorption equilibrium and kinetics for ethyleneethane separation with a novel solvent, Industrial and Engineering Chemistry Research 44 (2005) 7505-7510.

[4] R.T. Yang, Adsorbents: Fundamentals and Applications, first ed., WileyInterscience, Hoboken, N.J., 2003.

[5] T. Welton, P. Wasserscheid, Ionic Liquids in Synthesis, Wiley-VCH, Weinheim 2008.

[6] A. Kokorin, Ionic Liquids: Theory, Properties, New Approaches, InTech, Croatia, 2011.

[7] T. Welton, Room-temperature ionic liquids. Solvents for synthesis and catalysis, Chemical Reviews 99 (1999) 2071-2083.

[8] J.P. Hallett, T. Welton, Room-temperature ionic liquids: solvents for synthesis and catalysis. 2, Chemical Reviews 111 (2011) 3508.

[9] A. Ortiz, A. Ruiz, D. Gorri, I. Ortiz, Room temperature ionic liquid with silver salt as efficient reaction media for propylene/propane separation: Absorption equilibrium, Separation and Purification Technology 63 (2008) 311-318.

[10] A. Ortiz, L.M. Galán Sanchez, D. Gorri, A.B. De Haan, I. Ortiz, Reactive ionic liquid media for the separation of propylene/propane gaseous mixtures, Industrial and Engineering Chemistry Research 49 (2010) 7227-7233.

[11] A. Ortiz, L.M. Galán, D. Gorri, A.B. De Haan, I. Ortiz, Kinetics of reactive absorption of propylene in $\mathrm{RTIL}-\mathrm{Ag}^{+}$media, Separation and Purification Technology 73 (2010) 106-113.

[12] L.M. Galan, Functionalized ionic liquids. Absorption solvents for carbon dioxide and olefin separation, PhD dissertation. Eindhoven University of Technology, 2008.

[13] L.M. Galán Sánchez, G.W. Meindersma, A.B. Haan, Potential of silver-based room-temperature ionic liquids for ethylene/ethane separation, Industrial and Engineering Chemistry Research 48 (2009) 10650-10656.

[14] L.M. Galán, G.W. Meindersma, A.B. Haan, Potential of silver-based roomtemperature ionic liquids for ethylene/ethane separation, Industrial and Engineering Chemistry Research 48 (2009) 10650-10656.

[15] R. Li, H. Xing, Q. Yang, X. Zhao, B. Su, Z. Bao, Y. Yang, Q. Ren, Selective extraction of 1-hexene against $n$-hexane in ionic liquids with or without silver salt, Industrial and Engineering Chemistry Research 51 (2012) 8588-8597.

[16] C.L. Munson, L.C. Boudreau, M.S. Driver, W.L. Schinski, Separation of olefins from paraffins using ionic liquid solutions, US Patent 6623659 B2, 2003.

[17] J.F. Huang, H. Luo, S. Dai, A new strategy for synthesis of novel classes of roomtemperature ionic liquids based on complexation reaction of cations, Journal of the Electrochemical Society 153 (2006) J9-J13.

[18] J.F. Huang, H. Luo, C. Liang, D. Jiang, S. Dai, Advanced liquid membranes based on novel ionic liquids for selective separation of olefin/paraffin via olefinfacilitated transport, Industrial and Engineering Chemistry Research 47 (2008) 881-888.

[19] D.E. Jiang, S. Dai, First principles molecular dynamics simulation of a taskspecific ionic liquid based on silver-olefin complex: Atomistic insights into a separation process, Journal of Physical Chemistry B 112 (2008) 10202-10206.
[20] F. Agel, F. Pitsch, F.F. Krull, P. Schulz, M. Wessling, T. Melin, P. Wasserscheid, Ionic liquid silver salt complexes for propene/propane separation, Physical Chemistry Chemical Physics 13 (2011) 725-731.

[21] F. Pitsch, F.F. Krull, F. Agel, P. Schulz, P. Wasserscheid, T. Melin, M. Wessling, An adaptive self-healing ionic liquid nanocomposite membrane for olefinparaffin separations, Advanced Materials 24 (2012) 4306-4310.

[22] S. Werner, M. Haumann, P. Wasserscheid, Ionic liquids in chemical engineering, Annual Review of Chemical and Biomolecular Engineering 1 (2010) 203-230.

[23] R. Kato, J. Gmehling, Systems with ionic liquids: measurement of VLE and $\gamma^{\infty}$ data and prediction of their thermodynamic behavior using original UNIFAC, mod. UNIFAC(Do) and COSMO-RS(Ol), Journal of Chemical Thermodynamics 37 (2005) 603-619.

[24] M. Diedenhofen, A. Klamt, COSMO-RS as a tool for property prediction of IL mixtures - a review, Fluid Phase Equilibria 294 (2010) 31-38.

[25] M. Gonzalez-Miquel, J. Palomar, S. Omar, F. Rodriguez, $\mathrm{CO}_{2} / \mathrm{N}_{2}$ selectivity prediction in supported ionic liquid membranes (SILMs) by COSMO-RS, Industrial and Engineering Chemistry Research 50 (2011) 5739-5748.

[26] M. Miltner, A. Miltner, A. Friedl, Calculation of physical gas solubilities in various solvents using the COSMO-RS method, Chemie-Ingenieur-Technik 78 (2006) 1087-1092.

[27] J.-G. Rosenboom, W. Afzal, J.M. Prausnitz, Solubilities of some organic solutes in 1-ethyl-3-methylimidazolium acetate. Chromatographic measurements and predictions from COSMO-RS, Journal of Chemical Thermodynamics 47 (2012) 320-327.

[28] K.Z. Sumon, A. Henni, Ionic liquids for $\mathrm{CO}_{2}$ capture using COSMO-RS: Effect of structure, properties and molecular interactions on solubility and selectivity, Fluid Phase Equilibria 310 (2011) 39-55.

[29] J. Palomar, M. Gonzalez-Miquel, J. Bedia, F. Rodriguez, J.J. Rodriguez, Taskspecific ionic liquids for efficient ammonia absorption, Separation and Purification Technology 82 (2011).

[30] J. Palomar, M. Gonzalez-Miquel, A. Polo, F. Rodriguez, Understanding the physical absorption of $\mathrm{CO}_{2}$ in ionic liquids using the COSMO-RS method, Industrial and Engineering Chemistry Research 50 (2011) 3452-3463.

[31] Gaussian Inc., Gaussian 03, Revision C.02, 2004.

[32] GmbH\&CoKG, COSMOtherm C2.1 Release 01.11, G. Leverkusen 2010. <http:// www.cosmologic.de>.

[33] A. Navas, J. Ortega, R. Vreekamp, E. Marrero, J. Palomar, Experimental thermodynamic properties of 1-butyl-2-methylpyridinium tetrafluoroborate [b2mpy] $\left[\mathrm{BF}_{4}\right]$ with water and with alkan-1-ol and their interpretation with the COSMO-RS methodology, Industrial and Engineering Chemistry Research 48 (2009) 2678-2690.

[34] J. Palomar, J. Lemus, M.A. Gilarranz, J.J. Rodriguez, Adsorption of ionic liquids from aqueous effluents by activated carbon, Carbon 47 (2009) 1846-1856.

[35] Y.S. Kang, J.O. Won, H.H. Park, S.G. Oh, Solid state polymer electrolyte facilitated transport membranes containing surfactants, US Patent 6645276 B2, 2003. 